\title{
Do urethral Escherichia coli cause abacterial cystitis?
}

\author{
P WALPITA*, FP MARSH
}

From the Department of Nephrology, The London Hospital, London E1

SUMMARY To determine whether Escherichia coli in or near the urethra caused symptoms of abacterial cystitis, the results of serial cultures from the vaginal introitus of 92 patients with recurrent cystitis were compared with symptoms at clinic visits when they were abacteriuric. Similar comparisons were made in $\mathbf{1 5}$ of these patients using cultures from the external urethral meatus and proximal urethra. $E$ coli were grown from the vaginal introitus, urethral meatus and proximal urethra at 41,66 and $26 \%$ of visits respectively. Overall they were not significantly more often isolated when patients had cystitis, and the serotype was unrelated to symptoms.

$E$ coli was cultured significantly more often from the introital swabs of symptomatic intermittently bacteriuric (IB) women than from symptomatic persistently non-bacteriuric (NB) patients; and more often from symptomatic than from asymptomatic IB patients, although this difference was not significant. These findings were consistent with previous suggestions that symptoms of apparently "abacterial" cystitis in IB patients are due to occult coliform infection. We found no direct evidence that $E$ coli were the cause of symptoms in persistently non-bacteriuric women, or that urethral colonisation caused them. However $E$ coli were isolated from the introitus of control women only half as often as from both intermittently bacteriuric and persistently non-bacteriuric patients.

In only half the attacks of cystitis in women can evidence of bacterial growth in the urine be obtained using standard techniques, and the terms urethral syndrome, abacterial cystitis, ${ }^{1}$ frequencydysuria syndrome and symptomatic abacteriuria have been used to describe the remainder. Urinary infection with viruses, chlamydia, slow growing bacteria and low concentrations of coliforms, infection of the urethra itself, and stenosis of the urethral meatus have been suggested as possible causes of "abacterial" cystitis, the term used here. Many patients with bacterial cystitis later develop "abacterial" cystitis, ${ }^{2}$ which implies that one cause may underlie both illnesses. We have examined the possibility that $E$ coli within or near the urethra is responsible for the symptoms of "abacterial" cystitis.

\section{Patients, controls, and methods}

Ninety-two women, referred because of recurrent frequency and dysuria, were studied. They were reviewed at least monthly for six months, then less frequently if well. At each visit urinary symptoms

"Present address: Institute of Ophthalmology, London WC1. Accepted for publication 22 September 1982 were recorded and mid-stream urine (MSU) and a low vaginal swab (LVS) were taken for culture. Urine was also collected by suprapubic aspirate (SPA) at a quarter of the visits. In 15 women additional swabs were also taken from the external urethral meatus (superficial urethral swab: SUS), from the proximal part of the urethra (deep urethral swab: DUS), and from the rectum.

As controls, MSU and LVS cultures were done from each of 100 women who presented to a general practitioner with minor illness. They had had no urinary symptoms for two years, and had not taken antibiotics for at least one week.

\section{METHODS}

Low vaginal swabs were collected by passing a swab moistened with saline around the uncleaned margin of the vaginal introitus. Superficial urethral swabs were taken from the uncleaned external urethral meatus. Deep urethral swabs were collected, after cleaning the perineum with sterile saline, by passing a fine swab through a rigid sterile polypropylene catheter which was prevented from passing more than one centimetre into the urethra by a shield. Rectal swabs were taken at the same time. LVS and MSU specimens from patients were cultured as previously described. ${ }^{3}$ Urine from control 
subjects was cultured using dipslides. SUS, DUS and rectal swabs were plated directly and incubated aerobically overnight.

Coliform bacteria were identified according to Cowan and Steel. 4 E coli were serotyped using antisera to the following $O$ antigens: $1,2,3,4,6-13$, $15-25,68$ and 75.

Significant bacteriuria in patients was defined by any of the following findings: (i) Two consecutive MSU specimens culturing $\geqslant 10^{8} \mathrm{CFU} / \mathrm{l}$; (ii) one MSU specimen culturing $\geqslant 10^{8} \mathrm{CFU} / \mathrm{l}$, with an uncentrifuged urinary leucocyte concentration exceeding $10 / \mathrm{mm}^{3}$; (iii) one MSU specimen culturing $\geqslant 10^{8} \mathrm{CFU} / \mathrm{l}$, collected when there was pain during micturition; (iv) one suprapubic aspirate culturing any number of Gram-negative organisms. In the event of between $10^{7}$ and $10^{8} \mathrm{CFU} / \mathrm{l}$ being cultured from an MSU specimen, the possibility of infection was recognised, but considered "doubtful". Controls were considered not to be infected if their urine contained $<10^{7} \mathrm{CFU} / \mathrm{l}$. The presence of $E$ coli in low vagina, superficial urethra and deep urethra was not quantified.

"Abacterial" cystitis was defined as painful micturition or unaccustomed frequency, in the absence of significant bacteriuria, in a patient who had not taken an antibiotic for at least one week.

\section{SPECIMENS}

Six hundred and forty-three MSU and LVS culture pairs and 168 SUS and DUS culture pairs were made from patients. One hundred MSU and LVS culture pairs were made from the control women. Cultures made at a time of significant bacilluria or doubtful urine infection, within one week of antibacterial therapy, in subjects with vulval pruritus, or on the 15 occasions when symptoms or therapy were incompletely documented, were excluded. There remained for analysis 414 MSU and LVS cultures, and 68 SUS and DUS cultures from 92 patients aged $34 \pm 1.4 \mathrm{yr}$ (mean \pm SEM). Three hundred and twenty-seven of the LVS cultures came from 44 patients who had no evidence of significant bacteriuria during follow-up; these were called nonbacteriuric (NB) patients. Eighty-seven were taken
Table 1 Relation between symptoms of abacterial cystitis and $E$ coli in swabs from low vagina, superficial urethra and deep urethra

\begin{tabular}{llll}
\hline Specimen (No) & $\begin{array}{l}\text { Growth of } \\
\text { E coli }\end{array}$ & \multicolumn{2}{c}{ Symptoms of abacterial cystitis } \\
\cline { 3 - 4 } & & Present & Absent \\
\hline LVS (n = 414) & + & 28 & 141 \\
& - & 44 & 201 \\
SUS (n = 68) & + & 12 & 33 \\
& - & 6 & 17 \\
DUS (n = 68) & + & 4 & 14 \\
& - & 14 & 36 \\
\hline
\end{tabular}

The relation between symptoms and bacteriology at individual patient visits is shown.

from 48 patients who had significant bacteriuria at some time during follow-up, but at visits when their urine was not infected; these were called intermittently bacteriuric (IB) patients. After exclusions as above there remained MSU and LVS cultures from 82 controls aged $34 \pm 1.1 \mathrm{yr}$. Statistical analysis was done using the $\chi^{2}$ test and Student's paired $t$ tests, significance being defined as $p<0.05$.

\section{Results}

\section{RELATIONS BETWEEN SYMPTOMS OF}

ABACTERIAL CYSTITIS AND E COLI IN SWABS

FROM LOW VAGINA, SUPERFICIAL URETHRA

AND DEEP URETHRA

Escherichia coli were grown from low vaginal swabs at $41 \%$ of patient visits, from the superficial urethra at $66 \%$, and from the deep urethra at $26 \%$ of visits. Overall they were not significantly more often cultured from symptomatic patients (Table 1) and were cultured from IB and NB patients' swabs with a similar frequency. In NB patients the proportion of positive LVS taken at symptomatic visits (11/40 swabs) was less than that of swabs taken at asymptomatic visits (121/287 swabs), but the difference was not significant (Table 2). Although in IB patients a greater proportion of LVS was positive when patients were symptomatic (17/32 swabs) than when they were not (20/55 swabs) the difference

Table 2 Relation between symptoms of abacterial cystitis and E coli in swabs from the low vagina in non-bacteriuric and intermittently bacteriuric patients

\begin{tabular}{|c|c|c|c|c|}
\hline \multirow{2}{*}{$\begin{array}{l}\text { Growth of E coli in } \\
\text { low vaginal swabs }\end{array}$} & \multicolumn{2}{|c|}{ Symptoms in non-bacteriuric patients } & \multicolumn{2}{|c|}{ Symptoms in intermittently bacteriuric patients } \\
\hline & + & - & + & - \\
\hline $\begin{array}{l}+ \\
\bar{T} \\
\text { Total No of swabs }\end{array}$ & $\begin{array}{l}11^{*}(27) \\
29 \\
40\end{array}$ & $\begin{array}{l}121(42) \\
166 \\
287\end{array}$ & $\begin{array}{l}17^{*}(53) \\
15 \\
32\end{array}$ & $\begin{array}{l}20(36) \\
35 \\
55\end{array}$ \\
\hline
\end{tabular}

Figures in parentheses refer to the percentage of LVS swabs from which $E$ coli could be cultured in each group of patients. * $\mathrm{p}<0.05$. 
was not significant. However the proportion of positive LVS in symptomatic IB patients (17/32 swabs) was greater at a significant level $(0.05>p>$ 0.025 ) than that proportion in symptomatic (but not asymptomatic) NB patients (11/40 swabs). The number of superficial and deep urethral swabs taken from IB patients was too few to enable similar comparisons to be made.

RECOVERY OF E COLI FROM THE LOW VAGINAL SWABS OF CONTROL SUBJECTS

Escherichia coli were grown from the LVS of 18 of the 82 control women (22\%). This is significantly less than the proportion of positive swabs from the patients, whether all of these were considered (Table 2), or only the first LVS taken from each patient $(0.01>p>0.001)$. Of the latter group 43 of 92 were positive. The proportion of positive swabs in the controls was less than that in each of the patient sub-divisions; significantly so when compared with the symptomatic IB $(p<0.005)$ and asymptomatic NB $(\mathrm{p}<0.005)$ patients.

ISOLATION OF E COLI SEROTYPES FROM SWABS IN PATIENTS WITH AND WITHOUT SYMPTOMS Seventy to $82 \%$ of $E$ coli from the different areas could be typed with the available antisera. Twelve different serotypes were isolated. The heterogeneity of serotypes was greatest in $E$ coli derived from rectal swabs, least in those from urine, and intermediate in those cultured from the introitus and urethra. Serotype $\mathrm{O} 6$ was by far the commonest isolate; $\mathrm{O} 2$ was the only serotype which was more often than not associated with symptoms of "abacterial" cystitis; however this was because it was only cultured from one patient who was frequently symptomatic yet persistently abacteriuric.

\section{Discussion}

There is indirect evidence to suggest that the symptoms in bacterial and at least some forms of "abacterial" cystitis are due to similar causes. Thus the symptoms in each are qualitatively identical, although usually less severe when bacteriuria is not found, and often respond to treatment in the same way..$^{5-7}$ In a general practice survey $40 \%$ of women presenting with bacterial cystitis developed "abacterial" cystitis during follow-up, only $29 \%$ developing a recurrence of bacterial cystitis; many developed both. ${ }^{2} \mathrm{O}^{\prime} \mathrm{Grady}$ et $a^{8}$ also noted the occurrence of episodic "abacterial" cystitis in patients with recurrent bacterial cystitis; at such times their urine tended to contain leucocytes more often and in greater numbers than the urine of patients with similar symptoms but persistently uninfected urine. They considered that unrecognised $\overrightarrow{\vec{F}}$ bacterial infection might cause the symptoms in the $\stackrel{9}{\rightarrow}$ first group of patients. Such an explanation is supported by the work of Stamm et al ${ }^{9}$ who demonstrated $E$ coli and less often Staphylococcus $\frac{\bar{c}}{\bar{\phi}}$ saprophyticus in concentrations less than $3.4 \times 10^{7} / 1 \stackrel{\Phi}{\complement}$ in the suprapubic bladder aspirate of nearly half $๗$ their patients with "urethral syndrome" whose $\vec{\circ}$ mid-stream urine cultures showed no evidence of significant bacteriuria. They did not study asymp- $\vec{\omega}$ tomatic control women in the same way, but patients without pyuria were rarely so infected. Chronic ?유 inflammation in the lamina propria of the bladder is $\omega$ found in patients with recurrent bacterial and iv "abacterial" cystitis, but is less severe in the latter. ${ }^{10}$

Therefore, there is a possibility that unrecognised coliform infection of the lower urinary tract often 은 causes "abacterial" cystitis, unrecognised because of $\rightarrow$ its transience, or because of failure of the bacteria to $\mathbb{D}$ achieve high concentration in urine. We have tested the hypothesis that coliform infection of the urethra may cause symptoms of "abacterial" cystitis by relating our ability to culture $E$ coli from the ves- $\varnothing$ tibule and urethra of women with a history of frequent cystitis to the patients' symptoms at the same clinic visits. We did not quantify the $E$ coli from these areas, having found this unhelpful in predicting the development of urinary infection; ${ }^{3}$ the advantages of qualitative over quantitative analysis $\stackrel{\square}{\AA}$ of introital swabs have been emphasised by others. ${ }^{11}$ Overall, we were unable to relate symptoms to the $\frac{9}{3}$ growth of $E$ coli from swabs of vaginal introitus, external urethral meatus or proximal urethra. Our finding that $E$ coli were more likely to be isolated from LVS of symptomatic IB than symptomatic? NB patients may have been due to chance, for the difference was only weakly significant and $E$ coli were often isolated from such swabs taken from 0 asymptomatic NB patients. However it is compatible with previous suggestions that apparently "abacterial" cystitis in intermittently bacteriuric patients is due to coliform infection. Stamm et al, ${ }^{9}$. were usually able to isolate $E$ coli from the urethra $\stackrel{\sim}{\circ}$ and vagina of women with the "urethral syndrome" whose bladder urine contained low concentrations 0 of bacteria, but did not often find them in similar $\omega$ women with sterile bladder urine or in asymptomatic women. Cattell $e t a l^{12}$ noted no difference in periurethral $E$ coli carriage rate between persis- $\stackrel{\mathbb{D}}{\Phi}$ tently symptomatic abacteriuric patients, asymp- $\stackrel{?}{?}$ tomatic abacteriuric patients with a history of cystitis ${ }^{2}$ and patients with recurrent bacteriuric cystitis $\frac{O}{\mathbb{D}}$ studied between attacks of infection; they did not $\stackrel{?}{\stackrel{\rho}{P}}$ make cultures from the proximal urethra. In con- $\stackrel{\mathbb{Q}}{\Omega}$ trast, the same group had previously been able to 
relate symptoms of cystitis to the introital carriage of enterobacteria. ${ }^{13}$

We isolated $E$ coli twice as often from the introitus of our non-bacteriuric and intermittently bacteriuric patients as from control women, although their age distributions were similar. This differs from the findings of $\mathrm{O}^{\prime} \mathrm{Grady}^{13}$ and Cattell ${ }^{12}$ but agrees with those of others in patients with less well defined urinary infections. ${ }^{1415}$ The similar overall isolation rate in IB and NB patients suggests that although the presence of $E$ coli at the introitus is not associated with symptoms of cystitis it may denote lack of resistance to vulval and perhaps urethral bacterial colonisation in both groups, or more specifically may predispose to $E$ coli urine infection in both. It supports the possibility that the symptoms of apparent "abacterial" cystitis in both IB and NB patients may most often be due to occult coliform infection of the urinary tract, despite the differences claimed between them.

We detected $E$ coli much less often in the proximal urethra than at the urethral meatus. This implies that the urethra is inhospitable to bacteria in women as in men, or that it is difficult to culture bacteria from it. The former is suggested by the results of Mortimer et al, ${ }^{16}$ whose method of making cultures from the proximal urethra was similar to ours. They found bacteria in the proximal urethra only half as often as at the urethral meatus in abacteriuric antenatal patients. There was no reduction when bacteriuric antenatal patients were studied, implying that a urethral defence mechanism has been overcome in them.

We have also examined the possibility that some $E$ coli serotypes may be more likely than others to cause symptoms of "abacterial" cystitis, but found no evidence for this. The distribution of serotypes in urethra and introitus reflected that in the faeces, although it was less heterogeneous. ${ }^{17}$

Slow-growing microaerophilic organisms have been suggested to cause "abacterial" cystitis ${ }^{18}$ as have chlamydia. ${ }^{9}$ However, the former may often be isolated from the vestibule, urethra and urine of normal women, and were no more often cultured from the urine of symptomatic patients. ${ }^{1920}$ In many patients the cause remains unknown. Our results do not support the hypothesis that unrecognised colonisation of the urethra by $E$ coli is an important cause. They are compatible with the hypothesis that symptoms of "abacterial" cystitis in intermittently bacteriuric, and possibly in persistently "nonbacteriuric", women are often due to unrecognised coliform infection of the urine.

We are grateful to Dr K Schopflin for her help with the control subjects, and to the Special Trustees of the London Hospital for financial support.

\section{References}

${ }^{1}$ Medical Research Council Bacteriuria Committee. Recommended terminology of urinary tract infection. Br Med J 1979;ii:717-9.

${ }^{2}$ Manners BTB, Grob PR, Dulate C, Grieve NWT. The interrelationships of asymptomatic bacteriuria, acute bacterial pyelonephritis and bacterial cystitis in women. In: Brumfitt W, Asscher AW, eds. Urinary tract infection. London: Oxford University Press, 1973:186-94.

${ }^{3}$ Marsh FP, Murray M, Panchamia P. The relationship between bacterial cultures of the vaginal introitus and urinary infection. Br J Urol 1972;44:368-75.

4 Cowan ST, Steel KS. Manual for the identification of medical bacteria. 2nd ed. London: Cambridge University Press, 1965.

${ }^{5}$ Brooks D, Maudar A. Pathogenesis of the urethral syndrome in women and its diagnosis in general practice. Lancet 1972;ii:893-8.

${ }^{6}$ Marsh FP. The frequency-dysuria syndrome. In: Blandy JP, ed. Urology. Oxford: Blackwell Scientific Publications, 1976:734-52.

7 Tapsall JW, Taylor PC, Bell SM, Smith DD. Relevance of "significant bacteriuria" to aetiology and diagnosis of urinary tract infection. Lancet 1975; ;i:637-9.

' O'Grady FW, Charlton CAC, Fry IK, McSherry A, Cattell WR. Natural history of intractable "cystitis" in women referred to a special clinic. In: Brumfitt W, Asscher AW, eds. Urinary tract infection. London: Oxford University Press, 1973:81-91.

- Stamm WE, Wagner KF, Amsel R, et al $N$ Engl $J$ Med 1980;303:409-15.

${ }^{10}$ Marsh FP, Banerjee R, Panchamia P. The relationship between urinary infection, cystoscopic appearance and pathology of the bladder in man. J Clin Pathol 1974;27:297-307.

"Seddon JM, Bruce AW, Chadwick P, Carter D. Introital bacterial flora-effect of increased frequency of micturition. $\mathrm{Br} J$ Urol 1976;48:211-8.

${ }^{12}$ Cattell WR, McSherry MA, Northeast A, Powell E, Brooks JL, O'Grady FW. Periurethral enterobacterial carriage in pathogenesis of recurrent urinary infection. $\mathrm{Br}$ Med $J$ 1974;iv: 136-9.

${ }^{13}$ O'Grady FW, Richards B, McSherry MA, O'Farrell SM, Cattell WR. Introital enterobacteria, urinary infection and the urethral syndrome. Lancet 1970;ï:1208-10.

14 Fair WR, Timothy MM, Millar MA, Stamey TA. Bacteriologic and hormonal observations of the urethra and vaginal vestibule in normal pre-menopausal women. J Urol 1970;104:426-31.

is Bailey RR, Gower PE, Roberts AP, Stacey G. Urinary tract infection in non-pregnant women. Lancet 1973;ii:275-7.

${ }^{16}$ Mortimer WC, Mobbs GA, Boulton J. The bacterial content of the female urethra in pregnancy. Journal of Obstetrics and Gynaecology of the British Commonwealth 1967;74:579-82.

17 Walpita P. University of London: PhD thesis, 1979:82-105.

18 Maskell R, Pead L, Allen J. The puzzle of "urethral syndrome": a possible answer? Lancet 1979;i:1058-9.

19 Drabu YH, Sanderson PJ. Urine culture in urethral syndrome. Lancet 1980;i:37-8.

${ }^{20}$ Brumfitt W, Hamilton-Miller JMT, Ludlam H, Gooding A. Lactobacilli do not cause frequency and dysuria syndrome. Lancet 1981 ;ii:393-6.

Requests for reprints to: Dr FP Marsh, Department of Nephrology, The London Hospital, London E1 1BB, England. 